\title{
SLIDING MODE CONTROLLER FOR NONLINEAR /UNCERTAIN DYNAMICAL SYSTEMS
}

ff areed, K. M Soliman, s.f saraya, M. F ElBaz

\author{
Abstract \\ Tin's paper discusses tlie control problem of nonlinear/uncertain \\ dyiianiic systems for wliich the uncertainty in the dynamics is either unknown or \\ impossible via variable stnicture systems (VSS) with sliding mode approach. A \\ certain 'canonical fonn for tlie nominal linear model of uncertain system is \\ described in order to simplify the development of tlie design scheme. An algorithm \\ for deteniiining the subspace witliin wliich ideal sliding motion occurs is presented. \\ The aigoritlmi is based. on the Eigeiistructure assigtirnent to assign both the \\ eigenvalues and the associated eigenvectors to the closed loop feedback system \\ diu'ing sliding mode. The constraints on tlie selection of possible closed loop \\ eigenvectors are described. A specific subspace is identified- and the selected \\ eigenvectors must be located withm this subspace. The switcliing surfaces ai'e \\ designed so that the behavior of the system gives asymptotic stability during sliding \\ mode. A coiilrol structure is developed to guarantee the attainment of the sliding \\ mode in die presence of paraineter 2 'and distui'bances uncertainties. The control input \\ is selected such that any state outside tlie switcliing surface is driven to reach the \\ switching surface in finite time. The proposed conti'ol law consists of equivalent \\ control, and robust control. The equivalent control is designed such that the \\ nominal system of uncertain system exliibits a desirable dynamics. Tlie robust \\ control is then developed to guai'antee the reaching condition in the presence of \\ parameter \'ariations and external disturbances. The proposed controller is applied \\ numerically to regulate the en'ors in load-fi-equency conti'ol of an interconnected \\ two-area power generating systems connected together via a single transmission \\ line. Simulation results verify the validity of the proposed approach in tenns of \\ high robustness,
}

